\title{
Comprehensive food labelling for obesity control
}

\begin{abstract}
Obesity rates continue to increase and be linked to many chronic diseases worldwide Yet existing guidelines to help people achieve energy balance are difficult to implement. We propose a new energy unit (E-unit) of $80 \mathrm{kcal}$ such that healthy adults' caloric need (in energy units) can be calculated by a simple equation where the necessary energy units = body weight $(\mathrm{kg}) \times 0.4$ for daily intake throughout most of adult life including both sexes, the elderly and even pregnant women. This formula, in conjunction with the comprehensive food icon (FI), which is a colored guide for balanced nutrition used in Shokuiku (food and nutrition education) in Japan, will allow individuals to adjust their energy intake to achieve energy balance. The comprehensive food icon (FI) includes information about energy units, balance of major nutrients and antioxidant units (AOU) as a surrogate marker of vegetables and fruits. Widespread adoption and utilization of this food icon by food producers, suppliers and consumers will support people who want to control body weight.
\end{abstract}

Volume 4 Issue 3 - 2016

\author{
Azusa Hirakawa,' Melissa K Melby, ${ }^{2}$ Shaw \\ Watanabe' \\ 'Life Science Promoting Association, Japan \\ ${ }^{2}$ University of Delaware, USA
}

Correspondence: Shaw Watanabe, Life Science Promoting Association, 25-3-1004, Daikyo-cho, Shinjuku, Tokyo 160-0015, Japan, Tel +8I353797785, Fax +8I353797786,

Email watashaw@lifescience.or.jp

Received: November 13, 2016 | Published: March II, 2016

Keywords: energy unit, food icon, obesity control, nutrient, dietary therapy

Abbreviations: FI, food icon; AOU, antioxidant units; DLW, doubly labeled water; TEE, total energy expenditure; SCOP, saku control obesity program; PA, physical activity; BMI, body mass index; BMR, basic metabolic rate; EI, energy intake

\section{Introduction}

Obesity rates continue to increase throughout the world. ${ }^{1,2}$ Rates of overweight and obesity among adults have increased for both men (from $29 \%$ to $37 \%$ ) and women (from $30 \%$ to $38 \%$ ) in recent years. Overweight and obesity are linked to more deaths worldwide than underweight. Health risks such as cardiovascular disease, cancer and diabetes increase when a person's BMI exceeds $25 .^{3-11}$ In 2010, obesity and overweight were estimated to have caused 3.4 million deaths, most of which were from cardiovascular events. ${ }^{1}$

In Japan, Healthy Japan 21 was implemented by the Ministry of Health, Labour and Welfare in 2000. ${ }^{12}$ Activities were implemented nationwide, including expectations that local governments formulate goals to enable individual residents to attain good health. However, mid-term review revealed that obesity rates have increased not decreased. ${ }^{13}$ Thus, we need to consider more effective tools to improve obesity control and prevention.

\section{Obesity prevalence in Japan}

Concerns over increasing obesity rates in Japan stem from results of the National Nutrition Survey, which have shown increasing trends in overweight in several demographic groups. Increases in overweight have been largest in men in small towns. ${ }^{14}$ This is in contrast to women living in larger metropolitan areas, where there has been a decrease in weight. Japan uses a stricter cut-off for obesity (BMI $>25)$ compared to the US (where BMI $>=30$ is used), because incidence of obesityassociated chronic diseases increases in Japanese people with BMI $>25$. A range of causes have been proposed:
(i) overeating
(ii) errors of eating pattern
(iii) inactivity

(iv) heredity and

(v) disturbance in thermogenesis. ${ }^{15-17}$

\section{Population-level programs, education \& guidelines}

In response to increasing rates of obesity and associated chronic disease, Japan has implemented several policies, guidelines and programs. Kenkou Nippon 21 (Health Japan 21) began in 2000, ${ }^{18}$ followed by the Shokuiku (food and nutrition education) Basic Law which was passed in 2005. ${ }^{19,20}$ Subsequently, in 2008, the government launched a special health check-up (tokutei kenkou shinsa), involving measurement of waist circumference and nutrition counselling to reduce metabolic syndrome. ${ }^{13}$

Despite these programs and guidelines, obesity remains a public health problem in Japan. While nutrition and exercise scientists have documented required energy intake and expenditure, as described below, the form of the recommendations has not been 'userfriendly' enough to enable lay people to effectively implement the recommendations. Thus we propose a new Food Icon with associated energy unit that are easier to understand and use.

\section{Recommended energy intake in DRI 20 I5 in Japan}

Pooled analysis between health hazards and BMI showed that both total mortality and disease-specific mortality were lowest between BMI 21 and 25.-8 The DRI2010 in Japan showed reported recommended energy intake in kcal/day for age categories and physical activity (PA) levels. ${ }^{20}$ In DRI2015 reporting changed to recommend energy intake levels to maintain advisable BMI: 18.5-24.9 from 18-49years, 20.024.9 from $50-69$ years of age and $22.5-27.4 \mathrm{~kg} / \mathrm{m}^{2}$ for people 70 years and older. ${ }^{21}$

Body weight provides an individual with an easily- monitored indicator of the adequacy or inadequacy of habitual energy intake. Energy expenditure varies greatly among individuals as well as from day to day. In Japan, physical activity is divided into 3 categories and in the USA and Canada it is categorized into 4 levels: 1.0-1.39, 1.4$1.59,1.6-1.89,1.9-2.5 .{ }^{22}$ But Day-to-day variation in physical activity level varies up to $30 \%$ more than variation in dietary intake". ${ }^{23}$ 
In children and pregnant or lactating women the energy requirement includes the energy needs associated with the development of tissues or the secretion of milk at rates consistent with good health. ${ }^{24-29}$

\section{Accurate measurement of energy expenditure: Doubly Labeled Water (DLW) method}

Studies in whole-body calorimeters have been considered the most reliable measurement of energy expenditure. ${ }^{30-32}$ With information on total energy expenditure (TEE) derived using the doubly labeled water (DLW) method, it has become possible to accurately determine the energy expenditure of not only adults but also infants and children under free-living conditions. The most compelling evidence about underreporting of food intake, which can range from 10 to 45 percent, has come from measurements of TEE by the DLW method. ${ }^{33-35}$ TEE is relatively unaffected by fluctuations in energy balance. These changes are small and attenuate the effect of energy imbalances only modestly. ${ }^{33}$ We employed the DLW method to estimate TEE in 315 of people ranging in age from 20 to 75 and the available DLW data offered the best currently available information. ${ }^{21}$ When TEE was divided by body weight, the quotients were rather stable being $0.4 \mathrm{E}-$ unit/kg body weight (Table 1 ). This quotient was similar in the EPIC cohort study (Table 2).

Table I Total energy expenditure and physical activity by age category measured by double labelled water method (National Institute of Health and Nutrition)

\begin{tabular}{|c|c|c|c|c|c|c|c|c|}
\hline Sex & $\mathbf{N}$ & Occupation & Age & BMI & BMR & TEE & PA & Coefficient \\
\hline M & 10 & Graduates & $24.2 \pm 1.8$ & $22.1 \pm 1.1$ & $|786 \pm| 8 \mid$ & $2910 \pm 524$ & $1.6 \pm 0.3$ & 0.45 \\
\hline$M$ & 19 & Healthy adults & $25.1 \pm 2.7$ & $22.1 \pm 3.0$ & 1530 & $2631 \pm 373$ & $1.7 \pm 0.3$ & 0.41 \\
\hline M & 18 & Healthy adults & $33.8 \pm 3.3$ & $23.6 \pm 3.7$ & 1492 & $2655 \pm 526$ & $1.8 \pm 0.2$ & 0.41 \\
\hline$M$ & na & Healthy adults & $43.8 \pm 2.5$ & $24.4 \pm 2.6$ & 1546 & $258 I \pm 3 I I$ & $1.7 \pm 0.2$ & 0.40 \\
\hline M & 44 & Healthy adults & $51 \pm 14$ & $23.3 \pm 2.6$ & $1447 \pm 184$ & $2654 \pm 361$ & $1.9 \pm 0.3$ & 0.41 \\
\hline$M$ & 19 & Healthy adults & $53.3 \pm 2.5$ & $24.3 \pm 2.4$ & 1430 & $2445 \pm 311$ & $1.7 \pm 0.1$ & 0.38 \\
\hline$M$ & 8 & Elderly & $72.8 \pm 6.1$ & $22.4 \pm 2.5$ & 1505 & $2107 \pm 88$ & $1.4 \pm 0.1$ & 0.33 \\
\hline M & 19 & Healthy elderly & $73.4 \pm 4.1$ & na & $|480 \pm| 44$ & $2539 \pm 586$ & $1.7 \pm 0.3$ & 0.40 \\
\hline$M$ & 14 & Elderly volunteer & $74 \pm 6$ & $22.2 \pm 2.5$ & $1133 \pm 179$ & $1876 \pm 368$ & $1.7 \pm 0.2$ & 0.29 \\
\hline$M$ & 17 & Elderly at home & $82 \pm 3.1$ & $24.8 \pm 3.8$ & $1434 \pm \mid 43$ & $2294 \pm 311$ & $1.6 \pm 0.2$ & 0.36 \\
\hline $\mathrm{F}$ & 17 & Healthy adults & $24.9 \pm 2.7$ & $20.9 \pm 3.0$ & 1254 & $|98| \pm 36 \mid$ & $1.6 \pm 0.3$ & 0.31 \\
\hline $\mathrm{F}$ & 22 & Healthy adults & $33.7 \pm 2.8$ & $21.6 \pm 3.0$ & 1159 & $2039 \pm 394$ & $1.8 \pm 0.3$ & 0.32 \\
\hline $\mathrm{F}$ & 23 & Healthy adults & $44 \pm 3$ & $21.9 \pm 2.8$ & 1147 & $2008 \pm 234$ & $1.7 \pm 0.2$ & 0.31 \\
\hline $\mathrm{F}$ & 12 & Middle aged & $49.4 \pm 6$ & $20.9 \pm 1.9$ & $|188 \pm| 2 \mid$ & $1921 \pm 234$ & $1.6 \pm 0.1$ & 0.30 \\
\hline $\mathrm{F}$ & 16 & Tennis player & $50 \pm 4.8$ & $21.9 \pm 1.7$ & $1240 \pm 92$ & $2520 \pm 335$ & $2.0 \pm 0.2$ & 0.39 \\
\hline $\mathrm{F}$ & 15 & Healthy adults & $52.7 \pm 2$ & $22.7 \pm 1.5$ & 1103 & $1953 \pm 220$ & $1.8 \pm 0.2$ & 0.31 \\
\hline $\mathrm{F}$ & 10 & Healthy elderly & $73.3 \pm 3$ & na & $|22| \pm 9 \mid$ & $220 I \pm 354$ & $1.8 \pm 0.2$ & 0.34 \\
\hline $\mathrm{F}$ & 10 & Retired elderly & $74 \pm 4.4$ & $24.1 \pm 2.8$ & $1145 \pm 105$ & $|8| 4 \pm 2 \mid 3$ & $1.6 \pm 0.2$ & 0.28 \\
\hline MF & 12 & Healthy elderly & 73 & $25 \pm 3.0$ & $|37| \pm 20 \mid$ & $2366 \pm 342$ & $1.7 \pm 0.3$ & 0.37 \\
\hline
\end{tabular}

BMI, body mass index; BMR, basic metabolic rate; TEE, total energy expenditure; PA, physical activity

Table 2 Adaptability of E-unit system to European population. (EPIC Cohort Study)

\begin{tabular}{llllllll}
\hline Country & & $\mathbf{n}$ & Weight & EI_adj & sd & CV & Coefficient for unit \\
\hline Italy_Ragusa & M & 168 & 78.5 & 2677 & 675 & 0.25 & 0.43 \\
Itary_Florence & M & 27 I & 78.9 & 2656 & 677 & 0.25 & 0.42 \\
Italy_Turin & M & 677 & 77 & 2629 & 681 & 0.26 & 0.43 \\
Italy_Varese & M & 328 & 77.7 & 2764 & 678 & 0.25 & 0.44 \\
Germany_Heidelberg & M & 1033 & 83.6 & 2606 & 681 & 0.26 & 0.39 \\
Germany_Potsdam & M & 1235 & 82.6 & 2630 & 674 & 0.26 & 0.4 \\
Netherlands_Bilthoven & M & 1024 & 81.9 & 2640 & 694 & 0.26 & 0.4 \\
UK_General poplation & M & 404 & 80 & 2502 & 678 & 0.27 & 0.39 \\
UK_Health conscious & M & 114 & 77.9 & 2286 & 677 & 0.3 & 0.37 \\
\hline
\end{tabular}


Table Continued...

\begin{tabular}{llllllll}
\hline Country & & $\mathbf{n}$ & Weight & El_adj & sd & CV & Coefficient for unit \\
\hline Denmark_Copenhagen & M & 1356 & 83.1 & 2669 & 687 & 0.26 & 0.4 \\
Denmark_Aarhus & M & 567 & 82.8 & 2752 & 681 & 0.25 & 0.42 \\
Italy_Ragusa & F & 138 & 67.6 & 1980 & 519 & 0.26 & 0.38 \\
Itary_Naples & F & 403 & 67.5 & 2026 & 505 & 0.25 & 0.37 \\
Itary_Florence & F & 785 & 66 & 1965 & 486 & 0.25 & 0.38 \\
Italy_Turin & F & 392 & 63.6 & 1982 & 506 & 0.26 & 0.38 \\
Italy_Varese & F & 794 & 65 & 1939 & 481 & 0.25 & 0.38 \\
France_Southcoast & F & 612 & 60.4 & 1953 & 492 & 0.25 & 0.4 \\
France_South & F & 1396 & 60.2 & 2029 & 489 & 0.24 & 0.42 \\
France_Northwest & F & 622 & 60.8 & 2013 & 486 & 0.24 & 0.42 \\
France_Northeast & F & 2009 & 61.4 & 2040 & 486 & 0.24 & 0.41 \\
Total & & & & & & & 0.4
\end{tabular}

\section{El, Energy Intake}

The DLW-based evaluation of TEE provides the most accurate estimate of energy expenditure (Figure 1). The DLW data have been collected on a wide range of age groups and body sizes, so that estimated energy requirements can now be based on DLW measurements of TEE. ${ }^{33-39}$ Basal, resting and sleeping energy expenditures are related to body size and most closely correlated with the size of the fat-free mass. Energy expenditure is also affected by age, gender, nutritional state, inherited genetic polymorphisms and by endocrine differences. But the TEE values were usually within the range of individual daily deviation and can provide guidelines for recommended food intake. ${ }^{40}$

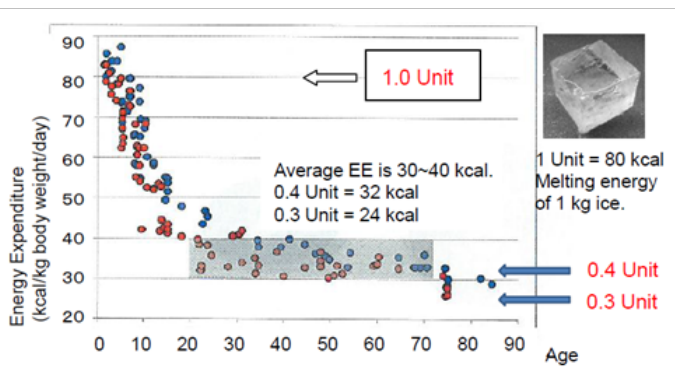

Figure I Total energy expenditure measured by ${ }^{2} \mathrm{H}_{2}{ }^{18} \mathrm{O}$ method (Summary of 139 reports by age with $\mathrm{BMI} 18.5 \sim 30.0$ and $\mathrm{PAL}<2.0$ ).

Energy expenditure ( $\mathrm{kcal} / \mathrm{kg}$ body weight/day) linearly decreases from birth to age 20years, then it becomes stable throughout the life. $0.4 \mathrm{E}$-unit for this range and 0.3 E-unit for older age would be an appropriate factor for intake of energy source.

\section{Balance between food intake and TEE}

There is a need to re-evaluate the amount of energy released from macronutrients by in vivo oxidation. The values of $4,9,4 \mathrm{kcal} / \mathrm{g}$ of carbohydrate, fat and protein, respectively, are still used widely in nutrition. The heat of combustion of carbohydrate and fat in a bomb calorimeter generally agrees with values from the Atwater system, but protein shows great variation. ${ }^{41-43}$ The energy derived by protein oxidation in a living body is less than the heat of combustion of protein, because the nitrogen-containing end product of metabolism is urea, which is excreted in the urine. ${ }^{44}$
Furthermore, as the thermal effect of protein is about $30 \%$, the in vivo energy value of protein should be less than $2.8 \mathrm{kcal} / \mathrm{g}$. The use of $4 \mathrm{kcal} / \mathrm{g}$ becomes a problem when energy intake is calculated in aging patients with sarcopenia or hypoalbuminemia. ${ }^{45}$ The difference between the estimated $4 \mathrm{kcal} / \mathrm{g}$ and the more accurate $2.8 \mathrm{kcal} / \mathrm{g}$ may result in energy insufficiency. Some intervention studies showing effects of a low carbohydrate and high protein diet may be explained by the difference of overestimated calorie intake. ${ }^{46}$

Humans can survive on diets providing widely varying proportions of carbohydrate, fat and protein. ${ }^{47,48}$ Large daily deviations from energy balance are readily tolerated and buffered primarily by energy stored in body fat. ${ }^{49}$

The coefficient of variation for intra-individual variability in daily energy intake is estimated to be $+/-23$ percent ${ }^{50}$ Variations in physical activity are not closely synchronized with adjustments in food intake. ${ }^{51}$ Thus, substantial positive as well as negative energy balances of several hundred $\mathrm{kcal} / \mathrm{d}$ regularly occur under free-living conditions among normal and overweight subjects. For many macronutrients, there are few direct data on the requirements of children. Most recommendations are based on extrapolations from adult values. ${ }^{20,21}$

\section{Dietary therapy for obesity control}

Various dietary therapies for reducing body weight have been proposed, such as macrobiotics, Atkins diet, Zone diet, Ornish Diet, Learn Diet, etc. ${ }^{52}$ These diets can be classified as: total energy restriction with natural raw foods, low carbohydrate diet, high protein diet and balanced diet. The relative proportion of macronutrients varies among these diets. We propose a tailor-made nutritional guideline which is based upon individual energy consumption. Recent nutritional therapy does not calculate protein as an energy source, because if enough energy is obtained from carbohydrates and lipids, protein is not burned to yield heat energy. ${ }^{53}$ The necessity of carbohydrate and lipid metabolism needs further study, as shown in metabolic changes between fasting therapy and ketone diet. ${ }^{47,54}$ Accordingly, protein requirement is independently calculated by body weight $\mathrm{x} 0.8 \mathrm{~g}$, if there is no renal insufficiency. ${ }^{21}$ 


\section{New energy unit to facilitate appropriate energy intake}

A new energy unit (E-unit), which is equivalent to the melting energy for $1 \mathrm{~kg}$ ice block $(80 \mathrm{kcal})$, was proposed for the new nutritional plan based on energy intake. ${ }^{55}$ Healthy adults need [body weight (kg) $\mathrm{x} 0.4$ ] and active people need [body weightx0.5] energy units to maintain energy balance. For example, a $60 \mathrm{~kg}$ man needs $24 \mathrm{E}-$ units, so $8 \mathrm{E}$-units can be eaten at breakfast, lunch and dinner. In children and adolescents, higher multipliers are used, with the appropriate multiplier being 1.0 for up to $10 \mathrm{~kg}$ body weight, 0.9 for up to $20 \mathrm{~kg}$, 0.8 for up to $30 \mathrm{~kg}, 0.7$ for up to $40 \mathrm{~kg}, 0.6$ for up to $50 \mathrm{~kg}$ and 0.5 for up to $60 \mathrm{~kg}$ (Figure $2 \mathrm{~A}$ ). The calculated values are in close agreement with those of the DRI2010. If the E-unit is shown on food labels and restaurant menus, it will facilitate the control of energy intake (Figure 2B). For example, if a person's body weight is $75 \mathrm{~kg}$, necessary energy intake would be $30 \mathrm{E}$-units $(75 \mathrm{x} 0.4)$, so the person may eat $10 \mathrm{E}$-units each for breakfast, lunch and dinner. If people remember this simple rule, the average intake amount will approximate the recommended amount (30E-unit in the above example) (Figure 3).

\section{Energy requirement/body weight (age 1-19)}

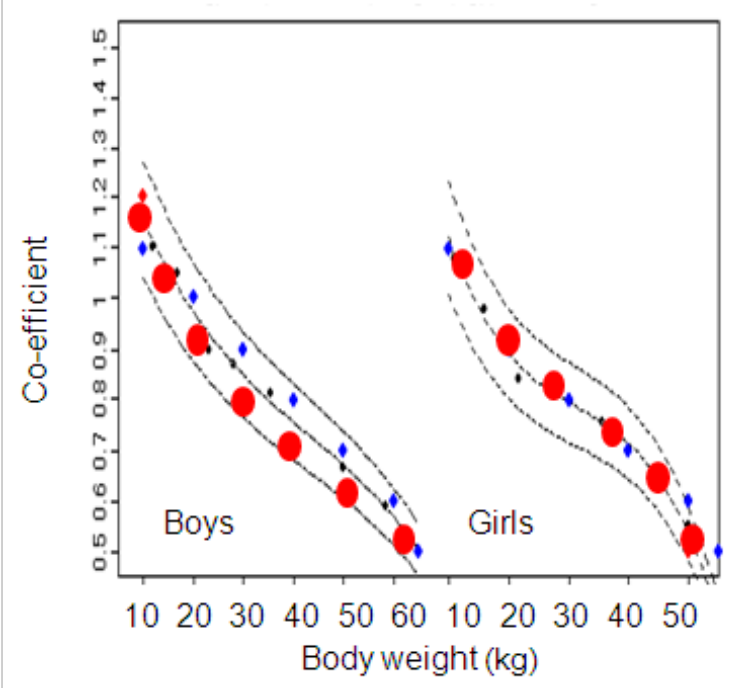

Figure 2A Good fitness between E-unit system (red circle) and estimated energy requirement for children by DRI20I0 (blue dot and range).

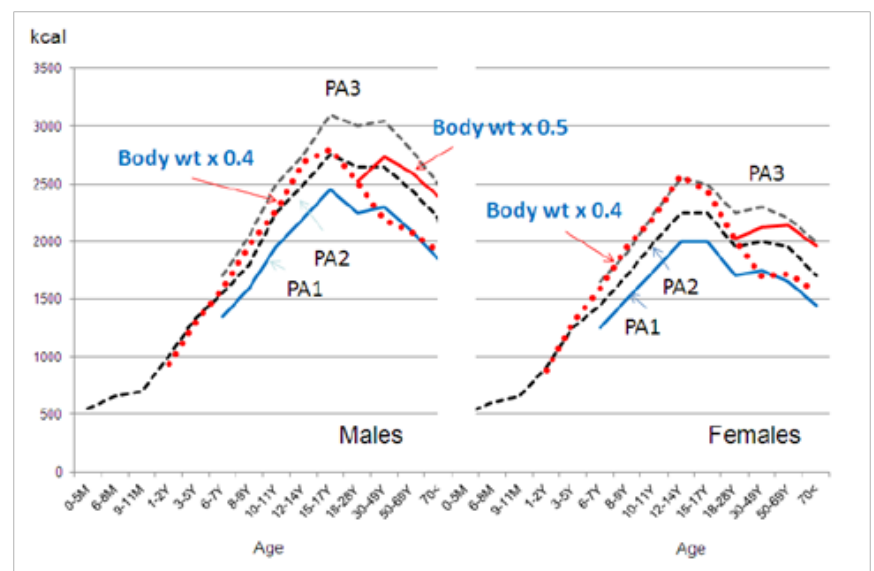

Figure 2B Good fitness between E-unit system (red circle) and estimated energy requirement by DRI20I0 throughout the life in both males and females. PA, physical activity

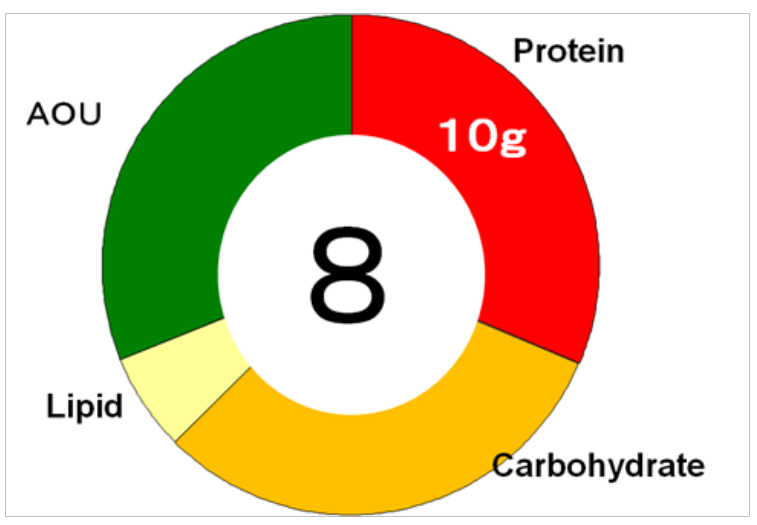

Figure 3 Comprehensive food icon.

Number of centre is E-unit. Weight of protein is described for low protein diet. AOU is a surrogate marker of vegetables and fruits (umole trolox

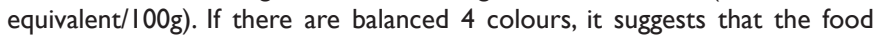
contains sufficient vitamins and minerals.

\section{Comprehensive food icon (FI)}

A three color guide for balanced nutrition, proposed by Toshiko Kondo, is used in Shoku-iku (food and nutrition education) at school. ${ }^{56}$ Yellow signifies food for energy, green signifies food for maintenance of the body and red signifies food for blood and muscle. Intake of specific foods such as $60 \mathrm{~g}$ beans (mame), $5 \mathrm{~g}$ sesame (goma), $40 \mathrm{~g}$ eggs (tamago), $200 \mathrm{~g}$ dairy (chichi), $10 \mathrm{~g}$ seaweed (wakame), $120 \mathrm{~g}$ vegetables and $150 \mathrm{~g}$ fruits (yasai), $60 \mathrm{~g}$ fish (sakana), $10 \mathrm{~g}$ mushroom (shiitake) and $100 \mathrm{~g}$ potatoes or yam (imo) are recommended by the mnemonic phrase "ma-go-ta-chi-wa-ya-sa-shi-i" which means "grandchildren are kind".

Recommended intake amounts are derived from the National Health and Nutrition Survey and nutrients were calculated using the 5th Foods Contents Table. ${ }^{57}$ Adequate nutrient intake of amino acids, essential oils, vitamins and minerals can be obtained by following the above schema. ${ }^{21}$ The proposed Food Icon (FI) utilizes this 3-color schema.

In addition to the energy unit in the center of the food icon (FI), the relative proportion of carbohydrate, protein and fat is shown in the outer circle based on weight (Figure 3). As vegetables and fruits have different weights, we employed antioxidant units (AOU) as a surrogate marker. AOU aims to measure the free-radical-reducing capacity of all antioxidants in the diet and takes into account synergistic effects between substances. ${ }^{58-60} \mathrm{We}$ defined the measured antioxidant capacity ( $\mu \mathrm{mol} \mathrm{TE} /$ day) in 242 foods and daily intake amount was calculated by 7-day weighed dietary records of 390 subjects over four seasons. ${ }^{61,62}$ TAC intake/day varied from 10,189 (summer) to 12,292 (winter). Vegetables (2827), fruits (2696) and beans (4151) were the three major sources. TAC can be used as a surrogate marker of vegetables and fruits intake.

For many nutrients, estimated requirements are based on balance, biochemical indicators and clinical deficiency data, because there is little information relating health status indicators to sufficiency or insufficiency of functional ingredients. If we obtain appropriate energy from diets based upon the FI system, the daily allowance of vitamins and minerals are usually achieved by consuming foods with 4 colours (magotachi-shoku). Although the units of AOU are different from those of the macronutrients, of the icon serves to convey the idea of balance, including micronutrients and functional food factors. 
Awareness of the balance of food colors facilitates healthy food choices.

\section{Importance of self-awareness and individualized tailor- made nutrition counselling}

Although control of total energy intake is essential to control obesity, individual awareness and practice are also important. ${ }^{63} \mathrm{We}$ developed a weight loss program based on a behavioral approach with dietary and exercise intervention (Saku Control Obesity Program (SCOP)) in Japan. ${ }^{64-66}$ In this program, we emphasized individualtailored counseling, instead of uniform instruction and the changes made in the diet and physical activity were designed for each participant. In the questionnaire, participants chose one of the five stages developed by Prochaska et al., ${ }^{66}$ pre-contemplation (participants are not seriously considering changing behavior), contemplation (participants are considering changing behavior, but they have no intention of carrying this out within the next month), preparation (participants are considering changing behavior and they will carry this out within the next month), action (participants have already changed behavior months) within the last 6months) and maintenance (participants have already changed behavior for at least 6 months. ${ }^{67,68}$ After one year intervention, $10 \%$ body weight reduction was achieved in more than half of the participants, for both males and females. ${ }^{68}$

\section{Cooperation of food providers and industries}

The food industry can play a significant role in promoting healthy diets by reducing the fat, sugar and salt content of processed foods. ${ }^{69,70}$ They can also provide useful and comprehensive information to consumers using the proposed FI (Figure 4). Food labels with detailed contents of nutrients are often too complicated and difficult to understand by ordinary consumers. Consumers primarily want to eat cheap and tasty foods and are generally not concerned with the exact nutrient content of foods. Ensuring that healthy and nutritious choices are available and affordable to all consumers will be easier if the FI becomes widely used. Fortunately, $80 \mathrm{kcal}=1$ unit size has been long used by the Japanese Diabetes Society and the Food Exchange Tables are popular among patients. ${ }^{71}$ Practicing responsible marketing, especially those aimed at children and teenagers, will also help. Standardized labeling system would be useful for consumers, providers (such as restaurant menus and bento (lunch) boxes) and food industries (Figure 5).

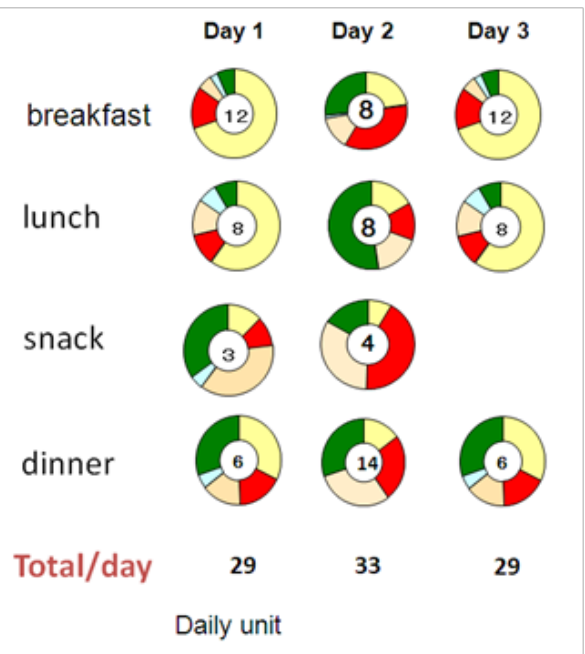

Figure 4A Daily intake of energy source by E-unit system. Consumers can remember how much he eats in one day in mind.
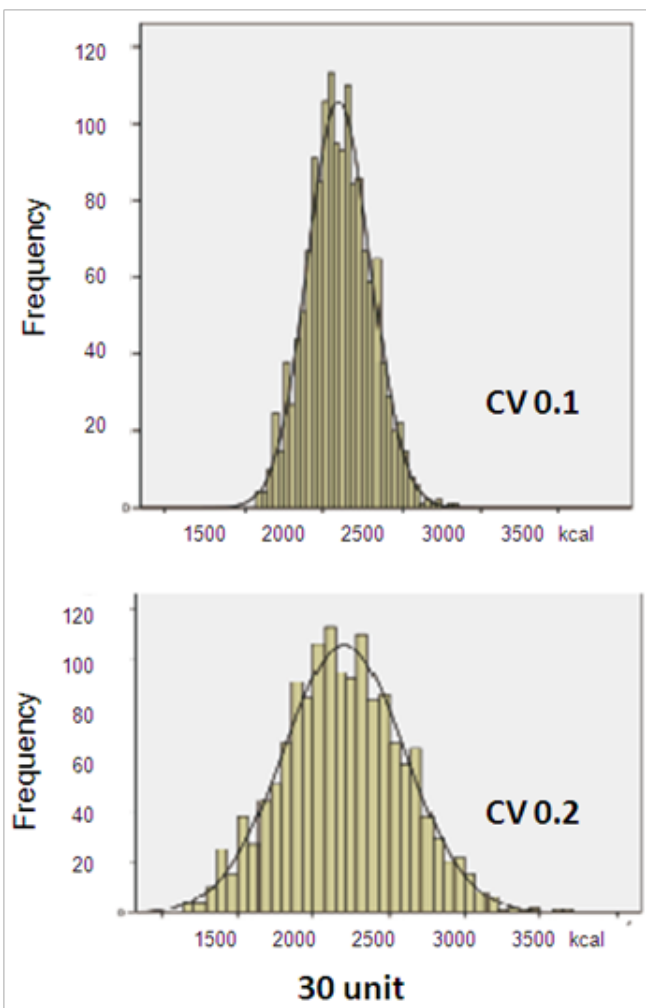

Figure 4B Distribution of daily energy source intake. If someone is allowed to take $30 \mathrm{E}$-unit a day, the average intake should centre to the mean by easy counting in mind.

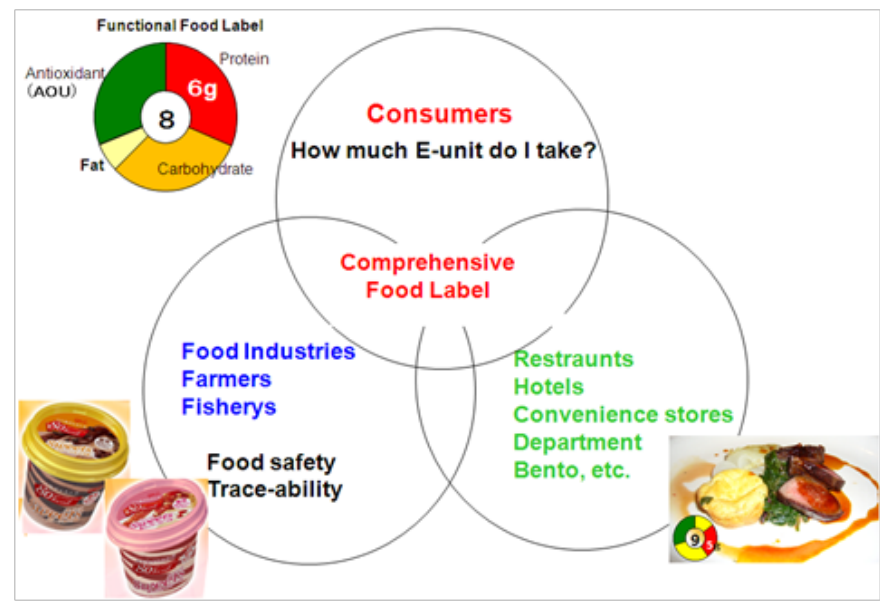

Figure 5 Standardized food icon is useful for consumers, food providers and food industries.

Left lower icecream is $80 \mathrm{kcal}$ (I E-unit) for diabetic patients. Right lower plate is sautéed duck with food icon. It shows $9 \mathrm{E}$-unit with good nutritional balance.

\section{Conclusion}

Control of energy intake is essential to maintain healthy body weight. However, the units of kcal or MJ are not easily used or measured in daily life. Serving size or portion size is used in many food guidelines, but these do not provide quantitatively accurate bases for consumption. Use of a new energy unit (1E-Unit=80kcal) leads to a simple equation where the necessary energy units = body weight ( $\mathrm{kg}) \mathrm{x} 0.4$ for daily intake throughout most of adult life including both sexes, the elderly and even pregnant women. For growing children, the 
coefficient is modified from 1 to 0.4 for body weight ranges starting at $10 \mathrm{~kg}$ and going up to $60 \mathrm{~kg}$. The comprehensive food icon (FI) includes information about energy units, balance of major nutrients and antioxidant units (AOU) as a surrogate marker of vegetables and fruits. Widespread adoption and utilization of this food icon by food producers, suppliers and consumers will support people who want to control body weight.

\section{Acknowledgements}

None.

\section{Conflict of interest}

The author declares no conflict of interest.

\section{References}

1. WHO Media Center. Obesity and overweight. 2015.

2. Ng M, Fleming T, Robinson M, et al. Global, regional and national prevalence of overweight and obesity in children and adults during 1980-2013:a systematic analysis for the Global Burden of Disease Study. Lancet. 2013;384(9945):766-781.

3. Whitlock G, Lewington S, Sherliker P, et al. Body-mass index and cause-specific mortality in 900000 adults: collaborative analyses of 57 prospective studies. Lancet. 2009;373(9669):1083-1096.

4. Berrington de Gonzalez A, Hartge P, Cerhan JR, et al. Body-mass index and mortality among 1.46 million white adults. $N$ Engl $J$ Med. 2010;363:2211-2219.

5. Tsugane S, Sasaki S, Tsubono Y. Under- and overweight impact on mortality among middle-aged Japanese men and women: a 10-y follow-up of JPHC study cohort I. Int J Obes Relat Metab Disord. 2002;26(4):529-537.

6. Tamakoshi A, Yatsuya H, Lin Y, et al. BMI and all-cause mortality among Japanese older adults: findings from the Japan collaborative cohort study. Obesity. 2010;18(2):362-369.

7. Sasazuki S, Inoue M, Tsuji I, et al. Body mass index and mortality from all causes and major causes in Japanese: results of a pooled analysis of 7 large-scale cohort studies. J Epidemiol. 2011;21(6):417-430.

8. Matsuo T, Sairenchi T, Iso H, et al. Age- and gender-specific BMI in terms of the lowest mortality in Japanese general population. Obesity. 2008; 16:2348-2355.

9. Lin WY, Tsai SL, Albu JB, et al. Body mass index and all-cause mortality in a large Chinese cohort. CMAJ. 2011;183(6):E329-E336.

10. Gu D, He J, Duan X, et al. Body weight and mortality among men and women in China. JAMA. 2006;295(7):776-783.

11. Jee SH, Sull JW, Park J, et al. Body-mass index and mortality in Korean men and women. $N$ Engl J Med. 2006;355(8):779-787.

12. Report of the Task Forces for Planning Healthy Japan 21 and Framing the Healthy Japan 21 Project. 2003.

13. Udagawa K, Miyoshi M, Yoshiike N. Mid-term evaluation of "Health Japan 21": focus area for the nutrition and diet. Asia Pac J Clin Nutr. 2008;17(Suppl 2):445-452.

14. Yoshiike N, Kaneda F, Takimoto H. Epidemiology of obesity and public health strategies for its control in Japan. Asia Pacific Journal of Clinical Nutrition. 2002;11:S727-S731.

15. Florentino RF. The burden of obesity in Asia: Challenges in assessment, prevention and management. Asia Pacific Journal of Clinical Nutrition. 2002;11:676-680.
16. Speakman JR, Westerterp KR. Associations between energy demands, physical activity and body composition in adult humans between 18 and 96y of age. Am J Clin Nutr. 2010;92(4):826-834.

17. Inoue $\mathrm{M}$, Iso $\mathrm{H}$, Yamamoto $\mathrm{S}$, et al. Daily total physical activity level and premature death in men and women:results from a large-scale population-based cohort study in Japan (JPHC study). Ann Epidemiol. 2008;18(7):522-530.

18. MHLW. Section 3. Measures against Lifestyle-Related Diseases through "Health Japan 21"and Promotion of "Shokuiku (food and nutrition education)". 2008.

19. CAO. (Shokuiku Basic Law and Shokuiku Promotion General Plan). Cabinet Office of Japan, 2012.

20. Watanabe S. Changes in dietary habits in Japan: Background of Shokuiku and its promotion. Clinical and Functional Nutriology. 2010;2:9-14.

21. Ministry of Health Welfare. Recommended dietary allowance for Japanese: dietary reference intakes. $6^{\text {th }} \& 7$ th ed. Tokyo: Ministry of Health and Welfare, Ministry of Health, Labour and Welfare, DRI2015. 2015.

22. The U.S. Government's Official Web Portal Department. CDC Facts about Physical Activity. 2014.

23. Ishikawa-Takata K, Tabata I, Sasaki S, et al. Physical activity level in healthy free-living Japanese estimated by doubly labelled water method and International Physical Activity Questionnaire. Eu J Clin Nutr. 2008;62(7):885-891.

24. Goldberg GR, Prentice AM, Coward WA, et al. Longitudinal assessment of energy expenditure in pregnancy by the doubly labeled water method. Am J Clin Nutr. 1993;57(4):494-505.

25. Kopp-Hoolihan LE, van Loan MD, Wong WW, et al. Longitudinal assessment of energy balance in well-nourished, pregnant women. Am J Clin Nutr. 1999;69(4):697-704.

26. Butte NF, Wong WW, Treuth MS, et al. Energy requirements during pregnancy based on total energy expenditure and energy deposition. $\mathrm{Am}$ J Clin Nutr. 2004;79(6):1078-1087.

27. Forsum E, Kabir N, Sadurskis A, et al. Total energy expenditure of healthy Swedish women during pregnancy and lactation. Am J Clin Nutr. 1992;56(2):334-342.

28. Champagne CM, Han H, Bajpeyi S, et al. Day-to-Day Variation in Food Intake and Energy Expenditure in Healthy Women: The Dietitian II Study. J Acad Nutr Diet. 2013;113(11):1532-1538.

29. Butte NF, Wong WW, Hopkinson JM. Energy requirements of lactating women derived from doubly labeled water and milk energy output. $J$ Nutr. 2001;131(1):53-58.

30. Schoeller DA, van Santen E. Measurement of energy expenditure in humans by doubly labeled water method. $J$ Appl Physiol Respir Environ Exerc Physiol. 1982;53(4):955-959.

31. Black AE, Bingham SA, Johansson G, et al. Validation of dietary intakes of protein and energy against 24hour urinary $\mathrm{N}$ and DLW energy expenditure in middle-aged women, retired men and post-obese subjects: comparisons with validation against presumed energy requirements. Eur J Clin Nutr. 1997;51(6):405-413.

32. Seale JL, Klein G, Friedmann J, et al. Energy expenditure measured by doubly labeled water, activity recall and diet records in the rural elderly. Nutrition. 2002;18(7-8):568-573.

33. Dugas LR, Harders R, Merrill S, et al. Energy expenditure in adults living in developing compared with industrialized countries :a meta-analysis of doubly labeled water studies. Am J Clin Nutr. 2011;93(2):427-441. 
34. Kroke A, Klipstein-Grobusch K, Voss S, et al. Validation of a selfadministered food-frequency questionnaire administered in the European Prospective Investigation into Cancer and Nutrition (EPIC) Study: comparison of energy, protein and macronutrient intakes estimated with the doubly labeled water, urinary nitrogen and repeated 24-h dietary recall methods. Am J Clin Nutr. 1999;70(4):439-447.

35. Livingstone MB, Coward WA, Prentice AM, et al. Daily energy expenditure in free-living children: comparison of heart-rate monitoring with the doubly labeled water (2H2 18O) method. Am J Clin Nutr. 1992;56(2):343-352.

36. Reilly JJ, Jackson DM, Montgomery C, et al. Total energy expenditure and physical activity in young Scottish children: mixed longitudinal study. Lancet. 2004;363(9404):211-212.

37. Reilly JJ, Lord A, Bunker VW, et al. Energy balance in healthy elderly women. Br J Nutr. 1993;69(1):21-27.

38. Rothenberg EM, Bosaeus IG, Steen BC. Energy expenditure at age 73 and 78 - a five year follow-up. Acta Diabetol. 2003;40(Suppl 1):S134 S138.

39. Fuller NJ, Sawyer MB, Coward WA, et al. Components of total energy expenditure in free living elderly men (over 75 years of age):measurement, predictability and relationship to quality-of-life indices. $\mathrm{Br} \mathrm{J} \mathrm{Nutr}$. 1996;75(2):161-173.

40. Gaillard C, Alix E, Salle A, et al. Energy requirements in frail elderly people: a review of the literature. Clin Nutr. 2007;26(1):16-24.

41. Watanabe S. Diet and exercise guideline for healthy elderly. Clin Funct Nutr. 2013;5:76-80.

42. Watanabe S. Easy access for the individual energy requirement. Clin Funct Nutr. 2013;5:76-80.

43. Watanabe S. Tailor-made nutrition (4) Diet programs for weight loss Clin Funct Nutriol. 2009;1(4):218-222.

44. Floegel A, Pischon T. Low carbohydrate-high protein diet. $B M J$ 2012;344:e380.

45. Watanabe S. Cardiovascular risk of high protein diet. Clin Funct Nutr 2012;4:186-191.

46. Watanabe S. Effect of low carbohydrate diet for obesity control. Clin Funct Nutr. 2014;6:300-303.

47. Cahill GF. Starvation in man. New Engl J Med. 1970;282(12):668-675.

48. Cordain L, Miller JB, Eaton SB, et al. Plant-animal subsistence ratios and macronutrient energy estimations in worldwide hunter-gatherer diets. Am J Clin Nutr. 2000;71(3):682-692.

49. Laffel L. Ketone bodies: a review of physiology, pathophysiology and application of monitoring to diabetes. Diabetes Metab Res Rev. $1999 ; 15(6): 412-426$

50. Bingham SA, Gill C, Welch A, et al. Comparison of dietary assessment methods in nutritional epidemiology: weighed records v. $24 \mathrm{~h}$ recalls, food-frequency questionnaires and estimated-diet records. $\mathrm{Br} J \mathrm{Nutr}$. 1994;72(4):619-643

51. Edholm OG, Adam JM, Healy MJ, et al. Food intake and energy expenditure of army recruits. Br J Nutr. 1970;24(4):1091-1107.

52. Thompson CA. Integrative medicine. In: Mahan LK, et al. editors. Krause's Food and the Nutrition Care Process. 13th ed. USA: Elsevier Inc; 2012. p. 291-305.
53. Byham-Gray LD. Weighing the evidence: energy determinations across the spectrum of kidney disease. J Ren Nutr. 2006;16(1):17-26.

54. Hirakawa A, Watanabe S, Tanaka S. Koda's fasting therapy: Energy balance and intestinal bacterial flora. Adv Food Tech Nutr Sci-Open J. 2015;1(5):112-123.

55. Watanabe S. Tailor-made nutrition "Magotachishoku”. Clin Funct Nutr. 2010;2:162-167.

56. Watanabe S. Tailor-made nutrition. Evaluation of three-color food guide. Clin Funct Nutr. 2010;2:163-164.

57. MEXT. Standard tables of food composition in japan-2010. 2010.

58. Prior RL, Hoang H, Gu L, et al. Assays for hydrophilic and lipophilic antioxidant capacity (oxygen radical absorbance capacity (ORAC(FL)) of plasma and other biological and food samples. J Agric Food Chem. 2003;51(11):3273-3279.

59. Prior RL, Wu X, Schaich K. Standardized methods for the determination of antioxidant capacity and phenolics in foods and dietary supplements. J Agric Food Chem. 2005;53(10):4290-4302.

60. Serafini M, Del Rio D. Understanding the association between dietary antioxidants, redox status and disease: is the total antioxidant capacity the right tool? Redox Rep. 2004;9(3):145-152.

61. Takebayashi J, Oki T, Chen J, et al. Estimated average daily intake of antioxidants from typical vegetables consumed in Japan: a preliminary study. Biosci Biotechnol Biochem. 2010;74(10):2137-2140.

62. Tatsumi Y, Ishihara J, Morimoto M, et al. Seasonal differences in total antioxidant capacity intake from foods consumed by a Japanese population. Eur J Clin Nutr. 2014;68(7):799-803.

63. Shaw K, O'Rourke P, Del Mar C, et al. Psychological interventions for overweight or obesity. Cochrane Database Syst Rev. 2005;2:CD003818.

64. Watanabe S, Morita A, Aiba N, et al. Study design of the Saku Control Obesity Program (SCOP). Anti-Aging Med. 2007;4:70-73.

65. Kawashima N, Watanabe S, Morita A, et al. Changes of Fat Volume and Adipocytokines by the Randomized Intervention Program for Obesity Control Program (SCOP). Diabetes Res Open J. 2015;1(5):136-146.

66. Prochaska JO, Velicer WF. The transtheoretical model of health behavior change. Am J Health Promot. 1997;12(1):38-48.

67. Nakade M, Aiba N, Suda N, et al. Behavioral change during weight loss program and one-year follow-up: Saku Control Obesity Program (SCOP) in Japan. Asia Pac J Clin Nutr. 2012;21(1):22-34.

68. Nakade M, Aiba N, Morita A, et al. What behaviors are important for successful weight maintenance? J Obes. 2012;2012:202037.

69. Watanabe S. What We Know From Shokuiku? The Japanese Spirit-Food and Nutrition Education in Japan. Cabinet Office, Government of Japan; 2010 .

70. Watanabe S. Current controversies around carbohydrate restriction and the risk of high-protein diets. Diabetes Res Open J. 2015;1(5):e7-e10.

71. Evidence-based Practice Guideline for the Treatment for Diabetes in Japan 2013. 